\title{
The distribution of the main stresses in the section of the ceramsite concrete fixed formwork block with four cells
}

\author{
Arturs Proskurovskis ${ }^{1}$, Levon Nazinyan ${ }^{1}$, Anna Tarasova $^{1}$, Nikita Belousov ${ }^{1}$, \\ Svetlana Belyaeva ${ }^{1}$, Olga Nikonova $^{1}$, Sergey Pavlov ${ }^{1}$, Olga Skvortsova ${ }^{1}$, \\ Aleksandr Panfilov' ${ }^{1}$ and Luka Akimov ${ }^{1,2, *}$ \\ ${ }^{1}$ Peter the Great St. Petersburg Polytechnic University, Polytechnicheskaya, 29, St. Petersburg, \\ 195251, Russian Federation \\ ${ }^{2}$ Politecnoco di Milano, 32 Piazza Leonardo da Vinci, Milano, 20133, Italian Republic
}

\begin{abstract}
One of the main issues in block design is the prediction of possible areas of crack formation and their further spread. In structural elements, one of the possible places of crack formation is stress concentrators, because, under an external load, significant local stresses arise in the cross-sections of such parts, which can lead to their destruction. This article discusses possible ways to refine the section to reduce the stress concentration in places of a sharp change in the section of the block. After modeling the distribution of the main stresses in the section in the Abaqus program, it was revealed that with a radius of rounding at the inner corners of the block cells, the maximum values of the main tensile stresses decrease significantly, as does their distribution zone. At the same time, the maximum values of the main compressive stresses increase slightly, and their distribution area increases significantly.
\end{abstract}

\section{Introduction}

One of the stages in the modern design of structures for various purposes is the forecast of their strength, endurance and reliability, taking into accounts the hydrogeological conditions and hydrophysical soil properties of the construction territory [1, 2]. In particular, during this process, potential places of formation and further growth of cracks are analyzed, since they lead to the destruction of the designed objects.

In the general case, many structural elements have sharp transitions and cutouts that disrupt their smooth geometry and create a significant concentration of stresses. Under the action of an external load, significant local stresses arise in the cross-sections of such parts, which can lead to their destruction. In [3-15], various methods for modeling crack formation are considered, both using manual calculations and using software systems using the finite element method.

*Corresponding author: coolhabit@yandex.ru 
In [4], a theoretical study of a crack by the Vickers index is carried out and two finite element models are developed, one of which is based on fracture mechanics, and the second on tensile stress criteria. Article [5] is devoted to the mechanism of cracking in blocks in asphalt pavements. It presents the results of identifying the causes of cracking of a threedimensional model of a block subjected to thermal stress. In [6], a new Python-based numerical tool is described and tested that implements the Sequential Linear Analysis (SLA) procedure, which can call Abaqus FEM software. The adaptability of crack detection models was considered in [7]. The authors of the article test the neural network on two separate sets of image data of cracks in concrete and asphalt and offer three methods of adapting the network to increase the accuracy of detection of cracks. In [8], the stages of developing an effective numerical method based on a model of a fiber-optic column for predicting the nonlinear development of crack widths in composite beams are presented. In [9], a new approach is proposed for modeling the mechanism of crack formation based on the study of the cohesive zone model (CZM). The authors of [10] develop a model of crack growth for calculating the fatigue characteristics of samples. The article [11] describes the reasons for the inaccuracy of the structural state control (SHM) method, such as damage geometry, location of sensors, and boundary conditions that allow the authors to solve this problem by using the updated Gaussian process (GP) measurement model in the framework of fracture prediction Based PF. The study [12] is devoted to the method of large-scale mechanical crack growth based on the parametric finite element submodel. The authors of [13] devoted an article to the experimental and numerical study of masonry beams reinforced externally using fiberglass reinforced strips (GFRP). For this study, finite element analysis (FE) was used taking into account the Drucker-Prager criterion, which was carried out using ABAQUS to predict the ultimate bearing capacity and the failure mode of masonry beams. In [14], an experimental program was conducted to study the mechanical behavior of masonry elements made of concrete and natural sisal fibers using the ABAQUS software package. The study [15] presented a numerical study of composite walls made of reinforced concrete structures using the ABAQUS universal finite element program (FE).

The authors of articles [16-18] give a calculation of the construction work by the finite element method. In [16], bending plates are calculated using the Reisner theory using the finite element method. The method is based on the fundamental principles of minimum additional energy and possible displacements. The study [17] presented a mixed variation formulation of static and dynamic problems for thin-walled beams, as well as a comparison of the numerical results of mixed and classical finite element methods. In [18], the finiteelement method was used to study the behavior of crack propagation in a sandwich-foam plate and to obtain the corresponding crack growth paths from the criterion of fracture mechanics.

Articles [19-20] present methods for optimizing stress concentrators in sections of structural parts. So, the authors of [19] achieved a reduction in weight and stress concentration without the need to repeat the generation of the numerical model by rounding the corners of the structural bracket. In the article [20], using the example of a cantilever beam and a structural bracket, the role of shape optimization in optimizing section stress concentrators is considered.

In [21-26], methods for calculating structures in work processes using software systems, including Abaqus, and estimation of calculations of software systems are presented. The article [21] presents the function of predicting fatigue for Abaqus, which allows predicting fatigue based on the results of the analysis of Abaqus FE. The authors of [22] provide detailed data on numerical models that were used to predict the performance of two wellequipped walls with wrapped surfaces $3.6 \mathrm{~m}$ high, provide physical test data that can be used to compare other numerical models, and highlight lessons learned during development models, and determine reasonable expectations of the accuracy of numerical models for 
models of similar complexity. In the study [23], the behavior of concrete beams after tension is studied using finite element analysis using the ABAQUS software. Article [24] is devoted to the analysis of transient thermal stresses to simulate the general shrinkage deformation of high-strength concrete (HSC) and high-strength concrete reinforced with steel fiber (SFRHSC) by. In [25], nonlinear finite element analysis and integral modeling were carried out based on tests of the horizontal cyclic load of four hollow stone walls with various built-in structural schemes. The authors of [26], using a new tensile test for separation, established a correlation between the functional signatures of the formwork surface and its tendency to adhere to the concrete. In the sources cited, various cases of crack formation and stress concentration processes are considered, however, so far, the topic of crack formation in cellular blocks of non-removable formwork of this kind is unsolved.

This article discusses possible ways to refine the section to reduce the stress concentration in places of a sharp change in the section of the block.

\section{Materials and methods}

In this article, the simulation of the occurrence and distribution of main stresses in a section of an expanded clay cell block of fixed formwork when a load of $15 \mathrm{MPa}$ is applied to it is conducted in the Abaqus software package using the finite element method $(\mu=0.2 ; \mathrm{E}=$ $23109 \mathrm{~Pa}$ ). In a previous study [3], it was revealed that, due to smoother geometry, the stress concentration in the places of a sharp change in the section of the block decreased. Based on this, as one of the possible options for enhancing the section, it was proposed to round the inner corners of the block cells. However, the issue of identifying the smallest rounding radius of the internal corners, which can significantly reduce both the stress concentration and material consumption, is still relevant. Therefore, stress distributions were simulated in 5 sections of the block with rounding radius of the internal corners 15 , 20, 25, 30, $35 \mathrm{~mm}$, respectively (Fig. 1).
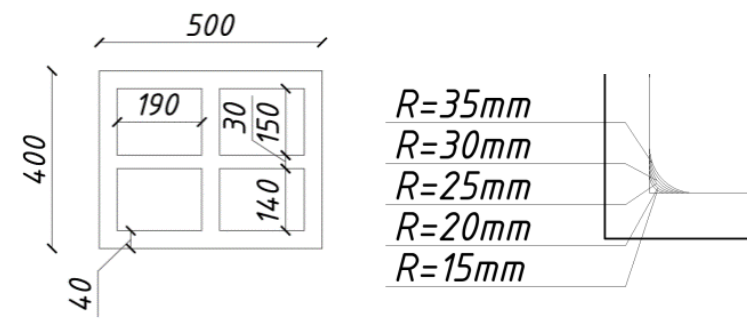

Fig. 1. The original version of the sectional block of fixed formwork. Top view and possible rounding radius of the internal corners of the block cells.

In the simulation, sections of the concentration of dangerous stresses were analyzed, and the nature of their propagation and their magnitude were examined. Then, based on these parameters, it was predicted whether the modified block would collapse or not.

\section{Results and discussion}

To compare the results, all data is summarized in one table (Table 1). For clarity, the resulting stress values are compared by the absolute deviation from the initial value of the unfinished section of the block (Fig. 2). 
Table 1. Maximum main compressive and tensile stresses in the section of the block

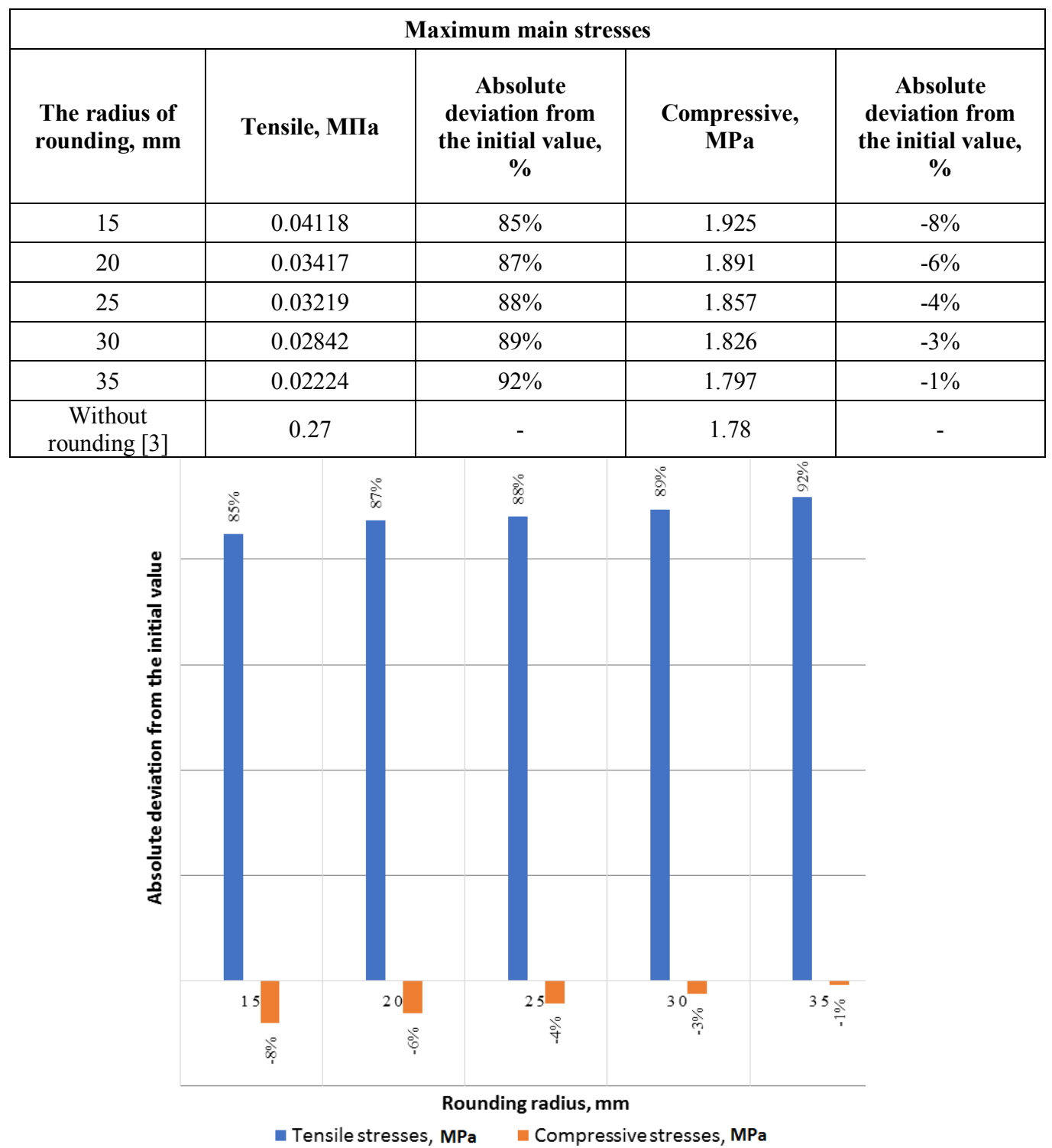

Fig. 2. Absolute deviation of the values of the maximum main compressive and tensile stresses from the initial values.

Thus, because of the appearance of the rounding radius, the values of the maximum main tensile stresses decreased by $85 \%$ with a radius of $15 \mathrm{~mm}$ and then decreased with an increasing radius. At the same time, the values of compressive stresses increased by $8 \%$ with a radius of $15 \mathrm{~mm}$ and then decreased with an increasing radius of rounding. Also, a comparison should be made of the distribution regions of the main tensile stresses in the section of the block. All cases are collected in Fig. 3. Thus, as the rounding radius increases, the distribution areas of the main tensile stresses and their values decrease. 


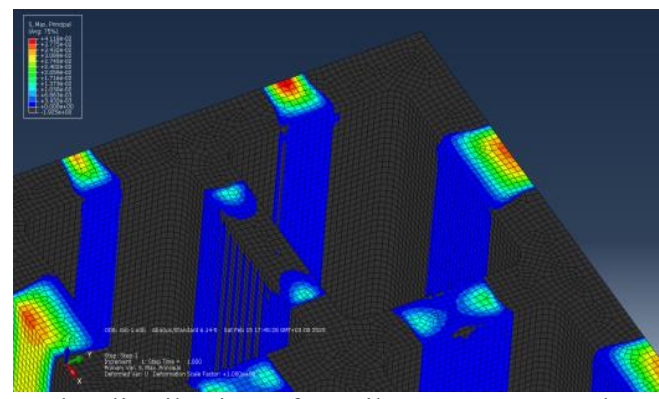

The distribution of tensile stresses over the cross-section of the block with $\mathrm{R}=15 \mathrm{~mm}$

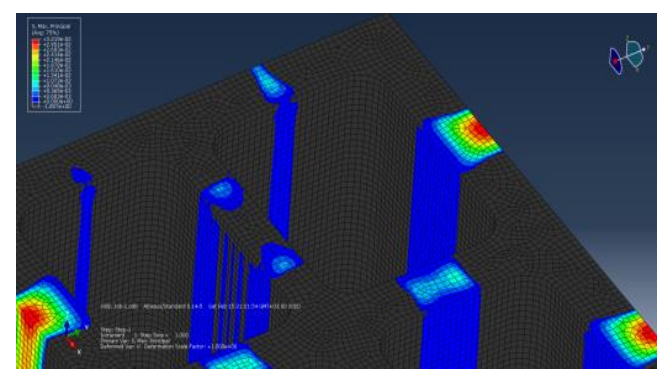

The distribution of tensile stresses over the cross-section of the block with $\mathrm{R}=25 \mathrm{~mm}$

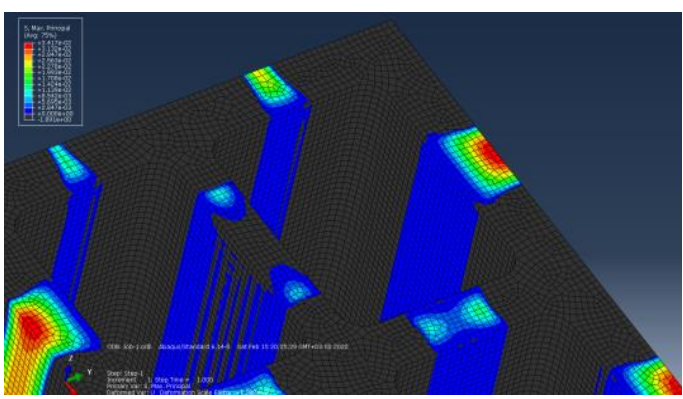

The distribution of tensile stresses over the cross-section of the block with $\mathrm{R}=20 \mathrm{~mm}$

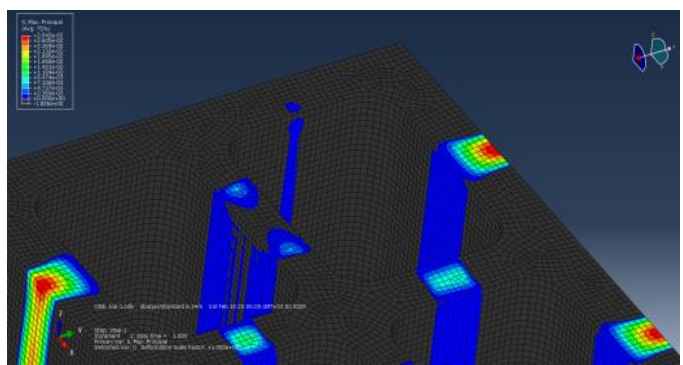

The distribution of tensile stresses over the cross-section of the block with $\mathrm{R}=30 \mathrm{~mm}$

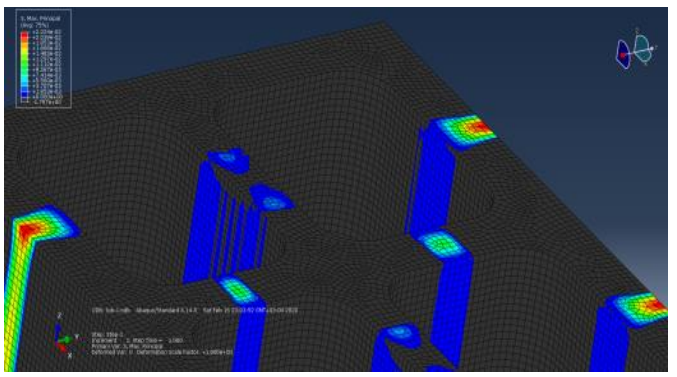

The distribution of tensile stresses over the cross-section of the block with $\mathrm{R}=35 \mathrm{~mm}$

Fig. 3. The distribution of main tensile stresses over the cross-section of the block with different rounding radiuses.

\section{Conclusions}

With an increasing radius of rounding, areas of the main tensile stresses and their values in these areas decrease. The values of the maximum main tensile stresses decrease significantly with an increasing radius of rounding. So, with a minimum radius, their values decreased by $85 \%$ compared with the unfinished block. However, with a further increase in the radius of rounding, the stress values decrease slightly and with an increase in the radius from 15 to $35 \mathrm{~mm}$, their values decrease by only $7 \%$.

The values of the maximum main compressive stresses increased. So, with a minimum rounding radius of $15 \mathrm{~mm}$, the values increased by $8 \%$. However, with a further increase in the radius, the absolute deviation from the initial value decreases and with a radius of 35 
$\mathrm{mm}$ it reaches only $1 \%$. The optimal rounding radius is $15 \mathrm{~mm}$ because it allows you to get the lowest values of the maximum main tensile stresses with the lowest material cost. A new unit with a modified cross-section with a radius of rounding of $15 \mathrm{~mm}$, will withstand the applied load.

\section{References}

1. V.V. Terleev, W. Mirschel, V.L. Badenko, I.Yu. Guseva, Eurasian Soil Science 50(4), 445-455 (2017)

2. V.V. Terleev, A.G. Topaj, W. Mirschel, Russian Meteorology and Hydrology 40(4), 278-285 (2015)

3. A. Proskurovskis, L. Nazinyan, A. Tarasova, V. Bespalov, B. Gaujena, Mater. Today Proc. (2020)

4. Y. Kadin, M. Mazaheri, V. Zolotarevskiy, C. Vieillard, M. Hadfield, J. Eur. Ceram. Soc. 39, 4011-4022 (2019)

5. H. Wang, W.G. Buttlar, Constr. Build. Mater. 206, 35-45 (2019)

6. L. Távara, L. Moreno, E. Paloma, V. Mantič, Compos. Struct. 225, 110993 (2019)

7. M. Alipour, D.K. Harris, Eng. Struct. 206, 110157 (2020)

8. L.Y. Xu, X. Nie, M.X. Tao, Constr. Build. Mater. 192, 357-365 (2018)

9. C. Li, J. Guo, Constr. Build. Mater. 214, 49-60 (2019)

10. R. Alyousef, T. Topper, A. Al-Mayah, Constr. Build. Mater. 166, 345-355 (2018)

11. J. Chen, S. Yuan, H. Wang, Mech. Syst. Signal Process. 140, 106646 (2020)

12. Y. Sun, J. Zhai, Q. Zhang, X. Qin, Eng. Fail. Anal. 102, 226-236 (2019)

13. I. Fayala, O. Limam, I. Stefanou, Compos. Struct. 152, 994-1006 (2016)

14. I. Soto Izquierdo, O. Soto Izquierdo, M.A. Ramalho, A. Taliercio, Constr. Build. Mater. 151, 98-112 (2017)

15. N.H. Nguyen, A.S. Whittaker, Numerical modeling of steel-plate concrete composite shear walls, Eng. Struct. 150, 1-11 (2017)

16. Y.Y. Tyukalov, Mag. Civ. Eng. 89, 61-78 (2019)

17. V.V. Lalin, V.A. Rybakov, S.S. Ivanov, A.A. Azarov, Magazine of Civil Engineering 89, 79-93 (2019)

18. Z. Li, B.L. Wang, S.L. Guo, J.E. Li, Int. J. Solids Struct. 176-177, 108-120 (2019)

19. S. Porziani, C. Groth, M.E. Biancolini, Procedia Struct. Integr. 12, 416-428 (2018)

20. C. Groth, A. Chiappa, M.E. Biancolini, Procedia Struct. Integr. 8, 379-389 (2018)

21. M. Nesládek, M. Španiel, Adv. Eng. Softw. 103, 1-11 (2017)

22. Y. Yu, R.J. Bathurst, T.M. Allen, Geotext. Geomembranes. 45, 237-249 (2017)

23. S.-H. Lee, A. Abolmaa, K.-J. Shin, H.-D. Lee, Journal of Building Engineering. 101273 (2020)

24. F. Bouziadi, B. Boulekbache, A. Haddi, C. Djelal, M. Hamrat, Constr. Build. Mater. 181, 381-393 (2018)

25. X. Zhou, J. Du, Q. Peng, P. Chen, Soil Dyn. Earthq. Eng. 126, 105815 (2019)

26. N. Spitz, N. Coniglio, M. El Mansori, A. Montagne, S. Mezghani, Surf. Coatings Technol. 352, 247-256 (2018) 